\title{
A lower body mass index is associated with cardiomyopathy in people with HIV infection: Evidence from a case comparison study
}

\author{
C E Lemmer, M Badri, M Visser, B M Mayosi
}

The cause of cardiomyopathy in patients infected with the human immunodeficiency virus (HIV) remains largely unknown, although a number of predisposing factors have been identified. Malnutrition has been postulated to be a contributory factor, but the association of anthropometric measures of nutritional status with HIV-associated cardiomyopathy has not been established.

Method. We investigated the association between anthropometric measures of nutritional status and cardiomyopathy in HIV-positive individuals in a cross-sectional case comparison study.

Results. Seventeen cases of HIV-associated cardiomyopathy and a comparison group of $18 \mathrm{HIV}$-positive individuals without cardiomyopathy were studied. There was no significant difference between the two groups in age, gender, CD4 cell count, HIV RNA viral load or World Health Organization (WHO) clinical stage of
HIV disease. Patients with HIV-associated cardiomyopathy had evidence of undernutrition compared with HIV-infected people without cardiomyopathy, as evidenced by a significantly lower body mass index (BMI) $\left(20.9 \mathrm{~kg} / \mathrm{m}^{2}\right.$ v. $\left.27.0 \mathrm{~kg} / \mathrm{m}^{2}, p=0.02\right)$, mid-upper arm circumference $(26.2 \mathrm{~cm}$ v. $27.3 \mathrm{~cm}, p=0.02)$, and bone-free arm muscle area $\left(26.7 \mathrm{~cm}^{2}\right.$ v. $\left.32.8 \mathrm{~cm}^{2}, p=0.02\right)$. However, in a multivariate stepwise logistic regression model, a lower BMI was the only independent anthropometric risk factor for cardiomyopathy (odds ratio 0.76, 95\% confidence interval $0.64-0.97, p=0.02$ ).

Conclusion. A lower BMI is associated with cardiomyopathy in people who are living with HIV.

S Afr Med J 2011;100:119-121.
Human immunodeficiency virus (HIV) infection is, with advancing immunosuppression, a risk factor for the development of heart failure due to dilated cardiomyopathy. ${ }^{1}$ In Africa, cross-sectional echocardiographic studies of HIV-infected individuals suggest a prevalence of cardiomyopathy varying from $9 \%$ in ambulant persons to $57 \%$ in hospitalised patients. ${ }^{2}$ Patients with HIV infection and dilated cardiomyopathy have a much worse prognosis than HIVpositive individuals with normal cardiac function. The negative prognostic impact of cardiac dysfunction in people living with HIV is reflected by a median survival to AIDS-related death of 101 days in patients with cardiomyopathy compared with 472 days in patients with a normal heart by echocardiography at a similar stage of infection without antiretroviral treatment. ${ }^{3}$

The cause of cardiomyopathy in black African patients infected with HIV remains largely unknown, although several predisposing factors have been identified. ${ }^{1,4}$ These include low socio-economic status, longer duration of HIV infection, lower CD4 cell count, higher viral load, low plasma selenium level, and advanced stage of HIV disease. ${ }^{5}$ Malnutrition has been postulated to be a contributory factor in the development of cardiomyopathy in HIV-infected individuals, but to the best of our knowledge the association of nutritional status with HIV-associated cardiomyopathy has not been established in appropriately designed studies. ${ }^{5}$

Department of Medicine, Groote Schuur Hospital and University of Cape Town C E Lemmer, BTech (Clin Tech)

M Badri, PhD

B M Mayosi, DPhil, FCP (SA)

Medical Research Council, Tygerberg, W Cape

M E Visser, BNutr, MPhil (Epidemiology)
We conducted a cross-sectional study among HIV-infected adults to determine whether there is an association between nutritional status, measured by simple anthropometric criteria that can be applied in routine clinical practice, and HIV-related cardiomyopathy. This investigation of the relationship between nutritional status and cardiomyopathy in HIV-positive patients may be relevant in the development of new therapeutic strategies, including restoration of adequate myocyte nutrition as a goal in the treatment of patients suffering from HIV-related heart failure.

\section{Methods \\ Design}

This was a cross-sectional study of 17 HIV-positive patients with cardiomyopathy and a comparison group of 18 HIV-positive individuals with no cardiomyopathy. The study was approved by the University of Cape Town (UCT) Health Sciences Faculty Human Research Ethics Committee (REC REF 016/2002), and all participants gave written informed consent.

\section{Selection of participants}

HIV-positive patients with and without cardiomyopathy were recruited from HIV clinics at Groote Schuur, New Somerset and G F Jooste Hospitals in Cape Town. Clinic attendees over the age of 18 years were invited to attend the Cardiac Clinic at Groote Schuur Hospital for clinical evaluation and examination by twodimensional guided M-mode echocardiography to identify those with cardiomyopathy. The two groups were matched for ethnicity as part of a study of genetic risk factors for cardiomyopathy in people with HIV infection. ${ }^{6}$ One experienced echocardiographer carried out all the echocardiographic examinations, using a calibrated ultrasound machine with a $2.5 \mathrm{MHz}$ transducer with subjects in the left lateral position. The echocardiographic examinations were read by one cardiologist (BMM).

Patients with dilated cardiomyopathy (a fractional shortening of $<25 \%$ and left ventricular internal dimension $>112 \%$ of predicted, according to Henry's formula) or patients with left ventricular dysfunction (a fractional shortening of $<25 \%$ and normal ventricular 
dimensions) were included in the study. ${ }^{7}$ Patients with valvular heart disease, hypertension, ischaemic, pericardial or congenital heart disease, diabetes or alcoholic cardiomyopathy and women who fulfilled the criteria for peripartum cardiomyopathy were excluded. Treatment with antiretroviral agents that have been implicated in cardiomyopathy ${ }^{8}$ was also grounds for exclusion.

Normal heart function was confirmed by echocardiography in all individuals in the comparison group.

\section{Laboratory tests}

CD4 cell counts were obtained by lymphocyte immunophenotyping using a flow cytometer in the Immunology Laboratory at Groote Schuur Hospital. The HIV viral load was measured by a quantitative polymerase chain reaction assay of viral genomic RNA using the Nasba kit in the Division of Virology at the University of Cape Town.

\section{Assessment of nutritional status}

The following anthropometric measurements were taken by the same observer: body weight (on an electronic scale to the nearest 0.2 $\mathrm{kg}$ ), height (on a portable stadiometer to the nearest $1 \mathrm{~mm}$, patient without shoes, feet parallel), mid-upper arm circumference (MUAC) (measured to the nearest $1 \mathrm{~mm}$ on the left arm using a standardised measuring tape - normal range is $>232 \mathrm{~mm}$ for women and $>243 \mathrm{~mm}$ for men), and triceps skinfold thickness (TSF) (to the nearest $0.2 \mathrm{~mm}$ using a Harpender caliper). Body mass index (BMI) (weight/height ${ }^{2}$, normal range 18.5 - 24.9) and bone-free arm muscle area (BF-AMA) (MUAC- $(3.14 \times$ TSF $))$ were calculated. ${ }^{9,10}$

\section{Statistical methods}

Categorical variables were compared using the $\chi^{2}$ test and continuous variables using the non-parametric Mann-Whitney test. The multivariate stepwise logistic regression model was used to identify independent anthropometric risk factors for cardiomyopathy. All tests were double-sided, and a $p$-value of $<0.05$ was considered significant.

\section{Results}

The clinical characteristics and nutritional status of the 17 patients with HIV-associated cardiomyopathy and the 18 HIV-infected individuals without cardiomyopathy are presented in Table I. There was no significant difference between the two groups with respect to age, gender, CD4 cell count, HIV viral load or World Health Organization clinical stage of HIV disease.

Although most participants presented with anthropometric parameters within the normal range, HIV-positive patients with cardiomyopathy had significantly lower values compared with HIVpositive patients without cardiomyopathy: BMI $20.9 \mathrm{~kg} / \mathrm{m}^{2}$ v. 27.0 $\mathrm{kg} / \mathrm{m}^{2}, p=0.02$; MUAC $26.2 \mathrm{~cm}$ v. $27.3 \mathrm{~cm}, p=0.02$; and BF-AMA $26.7 \mathrm{~cm}^{2}$ v. $32.8 \mathrm{~cm}^{2}, p=0.02$. However, in a multivariate stepwise logistic regression model, a lower BMI was the only independent anthropometric risk factor for cardiomyopathy (odds ratio $0.76,95 \%$ confidence interval $0.64-0.97, p=0.02$ ) (Table II).

\section{Discussion}

We showed that a lower BMI is associated with cardiomyopathy in people living with HIV. HIV infection profoundly affects nutritional status because it is associated with poor appetite, impaired nutrient absorption, increased basal metabolic rate and opportunistic infections. ${ }^{11}$ Under-nutrition in HIV patients is manifested by weight loss, loss of lean body mass and micronutrient deficiencies. We compared two groups of HIV-infected individuals who were well matched for the stage of HIV disease. The lower BMI is therefore likely to be independent of HIV infection, and linked to the cardiac disease.

Cardiac function is both affected by nutrition and can affect nutritional status. In a malnourished state, relative cardiac sparing occurs - this is especially apparent in chronic disease. ${ }^{11}$ Cardiac sparing occurs to preserve left ventricular function - even in patients with severe protein energy malnutrition, ventricular mass decreases but the ratio of ventricular mass to body weight remains constant. Heart disease can also have an adverse effect on nutritional status. Chronic heart dysfunction can result in cardiac cachexia, an inappropriate use of lean body mass instead of body fat that results in muscle wasting.

The major limitation of this study is that it cannot determine whether the lower BMI in HIV-associated cardiomyopathy is part of the causal pathway of cardiomyopathy or an effect of the cardiac dysfunction. Furthermore, the potential role of micronutrient deficiency in the pathogenesis of the cardiomyopathy was not investigated. When attempting to determine nutritional determinants of cardiomyopathy, it is important to measure micronutrient levels of substances such as selenium, which are implicated in ventricular function. ${ }^{12}$ Although selenium deficiency in healthy humans is uncommon, studies have documented a decline in selenium levels in the general HIV-infected population, possibly owing to the trapping of selenium by a selenoprotein encoded by the proviral genome. ${ }^{13,14}$ Low levels of selenium increase the ability of the Coxsackie virus to cause cardiac damage and ventricular dysfunction. ${ }^{12}$

The role of selenium in the pathogenesis of HIV-associated cardiomyopathy has been investigated. ${ }^{5,14,15}$ Chariot et al. investigated the involvement of antioxidant deficiencies in the occurrence of cardiac involvement in HIV-infected patients. ${ }^{16}$ Selenium status was significantly lower in the patients compared with the controls. Selenium supplementation resulted in echocardiographic improvement. There was an improvement of cardiac function after selenium supplementation in case reports involving paediatric AIDS patients. ${ }^{15}$ Finally, low selenium levels have been shown to be a significant factor in the development of HIV-associated cardiomyopathy in black African patients. ${ }^{5}$

This study extends the observations of micronutrient deficiency in HIV-associated cardiomyopathy to include lower BMI, a simple clinical measure of nutritional status that can be applied in resourcepoor circumstances of sub-Saharan Africa, which is the epicentre of the HIV/AIDS epidemic in the world. Although micronutrient measures were not performed in this study, our results are consistent with the observation that micronutrient deficiency is predictive of cardiomyopathy in people who are living with HIV infection. These preliminary findings, taken together with the small trials of selenium supplementation in HIV-associated cardiomyopathy, have important implications for the development of new therapies in this field. The time has come to consider the role of nutritional interventions in HIV-associated cardiomyopathy, including the restoration of adequate myocyte nutrition as a goal in treating patients suffering from HIV-related heart failure.

This paper is dedicated to the memory of the late Mr Peter Kaye, the echocardiographer who worked pro bono on this project. The expert assistance and contributions of Sister Maitele Tshifularo, Ms Lebogang Montewa, Dr Innocent Monya-Tambi, Ms Terry del Fabbro and Professor Gary Maartens are acknowledged with gratitude. The study was funded in part by the Medical Research Council and the National Research Foundation. 
Table I. Clinical characteristics and nutritional status of HIV-infected patients with cardiomyopathy and a comparison group of HIV-infected patients without cardiomyopathy

\begin{tabular}{|c|c|c|c|}
\hline Characteristic & $\begin{array}{l}\text { Cardiomyopathy } \\
(N=17)\end{array}$ & $\begin{array}{l}\text { No cardiomyopathy } \\
(N=18)\end{array}$ & $p$-value ${ }^{\star}$ \\
\hline Age (yrs) (median (IQR)) & $34.5(29.2-45.8)$ & $36.0(31.0-42.0)$ & 0.92 \\
\hline Gender $(N(\%))$ & & & $0.53^{\dagger}$ \\
\hline Male & $13(76.5)$ & $8(44.4)$ & \\
\hline Female & $4(23.5)$ & $10(55.6)$ & \\
\hline CD4 count $($ cells/ $\mu \mathrm{l})(N(\%))$ & & & $0.06^{\dagger}$ \\
\hline$<200$ & $6(32.3)$ & $12(66.7)$ & \\
\hline$\geq 200$ & $11(67.7)$ & $6(33.3)$ & \\
\hline $\begin{array}{l}\text { RNA viral load }\left(\log _{10}\right) \text { (median } \\
(\mathrm{IQR}))\end{array}$ & $5.20(4.6-5.64)$ & $4.81(3.52-5.50)$ & 0.22 \\
\hline WHO clinical stage $(N(\%))$ & & & $0.53^{\dagger}$ \\
\hline Stage 1 & $3(17.6)$ & $2(11.1)$ & \\
\hline Stage 2 & $4(23.5)$ & $6(33.3)$ & \\
\hline Stage 3 & $5(29.4)$ & $8(44.4)$ & \\
\hline Stage 4 & $5(29.4)$ & $2(11.1)$ & \\
\hline NYHA functional class $(N(\%))$ & & & $<0.0001^{\dagger}$ \\
\hline Class 1 & $3(18.8)$ & $18(100)$ & \\
\hline Class 2 & $6(37.5)$ & 0 & \\
\hline Class 3 & $5(31.3)$ & 0 & \\
\hline Class 4 & $2(12.5)$ & 0 & \\
\hline LVEF (median (IQR)) & $35.0(24.3-45.0)$ & $69.5(62.3-72.0)$ & $<0.0001$ \\
\hline LVIDd (median (IQR)) & $5.9(5.4-6.4)$ & $4.4(3.8-4.7)$ & $<0.0001$ \\
\hline BMI (median (IQR)) & $20.9(18.2-25.1)$ & $27.0(21.5-29.9)$ & 0.02 \\
\hline MUAC (median (IQR)) & $26.2(22.8-30.6)$ & $27.3(24.2-34.2)$ & 0.02 \\
\hline TSF (median (IQR)) & $11.35(9.38-33.6)$ & $16.3(7.8-34.6)$ & 0.44 \\
\hline BF-AMA (median (IQR)) & $26.7(14.5-32.0)$ & $32.8(27.0-42.4)$ & 0.02 \\
\hline \multicolumn{4}{|l|}{ 'Mann-Whitney test, unless otherwise stated. } \\
\hline
\end{tabular}

Table II. Stepwise logistic regression analysis for risk factors of dilated cardiomyopathy in HIV-infected patients

\begin{tabular}{lll}
\hline Factor & OR $(95 \% \mathrm{CI})$ & $p$-value \\
\hline BMI & $0.76(0.64-0.97)$ & 0.02 \\
$\mathrm{CD} 4$ count $($ cells $/ \mu \mathrm{l})$ & \\
$<200$ & $0.20(0.04-1.01)$ & 0.05 \\
$\geq 200$ & 1 \\
& \\
$\begin{array}{l}\text { OR = odds ratio; } \mathrm{CI}=\text { confidence interval; BMI = body mass index; } \mathrm{IQR}=\text { interquartile } \\
\text { range. }\end{array}$
\end{tabular}

\section{References}

1. Ntsekhe M, Mayosi BM. Cardiac manifestations of HIV infection - the African perspective. Nat Clin Pract Cardiovasc Med 2009;6:120-127.

2. Magula NP, Mayosi BM. Cardiac involvement in HIV-infected people living in Africa: a review. Cardiovasc J S Afr 2003;14:231-237.

3. Currie PF, Jacob AJ, Foreman AR, Elton RA, Brettle RP, Boon NA. Heart muscle disease related to HIV infection: prognostic implications. BMJ 1994;309:1605-1607.
4. Ansari AA, Sundstrom JB. Pathogenesis of AIDS-related dilated cardiomyopathy. AIDS Rev 2001;3:36-43.

5. Twagirumukiza M, Nkeramihigo E, Seminega B, Gasakure E, Boccara F, Barbaro G. Prevalence of observational, prospective, cohort study in Rwanda. Curr HIV Res 2007;5:129-137.

6. Shabooden G, Engl ME Syed FE Po ilton J Badri M Mayosi BM. The mitocho dis DNA T16189C polymorphism and HIV-associated cardiomyopathy: a genotype-phenotype association study. BMC Medical Genet 2009;10:37.

7. Mahon MG, Zal B, Arnoa G, et al. Absence of viral nucleic acids in early and late dilated cardiomyopathy. Heart 2001;86:687-692.

8. Herskowitz A, Willoughby S, Schulman SJ, Bartlett JD, Baughman KL. Cardiomyopathy in HIV infected patients associated with antiretroviral therapy: a report of six cases. Ann Intern Med 1992;116:311 313.

. Heymsfield SB, McManus C, Smith J, Stevens V, Nixon DW. Anthropometric measurement of muscle mass: revised equations for calculating bone free arm muscle area. Am J Clin Nutr 1982;36:680-690. 10. Frisancho AR. Anthropometric Standards for the Assessment of Growth and Nutritional Status. Ann Arbor: University of Michigan Press, 1990.

11. Miller TL, Gorbach SL. Nutritional Aspects of HIV Infection. London: Arnold, 1999.

12. Lipshultz SE. Dilated cardiomyopathy in HIV-infected patients. N Engl J Med 1998:339:1153-1155.

13. Baum MK, Shor-Posner G, Lai S, et al. High risk of HIV-related mortality is associated with selenium deficiency. J Acquir Immune Defic Syndr Hum Retrovirol 1997;15:370-374.

14. Chariot P, Perchet H, Monnet I, et al. Dilated cardiomyopathy in HIV-infected patients. N Engl J Med 1999;340:732-735.

15. Rerkpattanapipat $\mathrm{P}$, Wongpraparut $\mathrm{N}$, Jacobs LE, Kotler MN. Cardiac manifestations of acquired immunodeficiency syndrome. Arch Intern Med 2000;160:602-608.

16. Chariot P, Bignani O. Muscle involvement in human immunodeficiency virus-infected patients is associated with marked selenium deficiency. Muscle Nerve 1997;20:386-389.

Accepted 10 November 2011. 